Session \# 2793

\title{
A Senior Capstone Project in Pump System Design
}

\author{
Charles H. Forsberg \\ Department of Engineering, Hofstra University, Hempstead, NY 11549
}

\begin{abstract}
Hofstra University recently received a grant from the American Society of Heating, Refrigerating, and Air-Conditioning Engineers (ASHRAE) for students to design and build a pump system demonstration unit for the mechanical engineering laboratories. The grant was awarded through ASHRAE's Undergraduate Senior Project Grant Program. Senior mechanical engineering students designed and built the pump system as their capstone design project in the thermofluids area - one of two such design projects required of seniors.
\end{abstract}

The objective of the project was to construct a pump unit incorporating two variable speed pumps which could be operated individually, in a series arrangement, or in a parallel arrangement. Sufficient instrumentation was to be provided to enable determination of the headflow characteristics of the pumps in all the various configurations, and also the pump efficiencies. The unit was also to be portable and mounted on a cart so it could be used in classroom demonstrations in addition to being part of the laboratories. The ASHRAE grant provided the very welcome means of obtaining the desired experiment while giving the students a meaningful design experience which extended the students' knowledge gained previously through lecture courses in fluid mechanics and instrumentation.

This paper describes the design and construction experience. It discusses the various alternatives considered by the students in the system design, and provides details of the final selected design, including parts list. It also describes the students' experience in project construction. This information should be very useful to faculty desiring to add such an experiment to their labs.

Moreover, the paper describes non-technical aspects of the project. The project ultimately was very successful, with the pump experiment being incorporated into the mechanical engineering laboratories and used regularly in lab courses. Nevertheless, several problems were encountered during the endeavor. These problems were related to project organization and scheduling; interactions between faculty, students, and lab technicians; equipment procurement; division of work among the students; and the students' abilities and motivation. The paper discusses the problems and makes suggestions for avoiding or at least minimizing such problems in future similar activities. This information should be very useful to faculty in planning and directing senior capstone design courses, regardless of topic.

"Proceedings of the 2002 American Society for Engineering Education Annual Conference \& Exposition, Copyright 2002, American Society for Engineering Education" 


\section{Objective}

This paper describes a senior capstone project in pump system design recently undertaken by mechanical engineering students at Hofstra University. There were two main objectives: to provide a meaningful design experience for the students and to construct a system to be used in the mechanical engineering labs as a pump experiment.

Three students participated in the design project, which was assigned in the three-semester-hour course, ENGG 143 F, "Mechanical Engineering Design: Thermal and Fluid Systems". This course is typically taken by students in their last semester before graduation.

The paper first describes the pump system design and construction. It then discusses nontechnical aspects of the course, including problems encountered. It makes suggestions for avoiding or minimizing the problems in future similar courses.

\section{Pump System Design}

\section{A. Design Criteria}

The following pump system design criteria were given to the students at the first class session:

1) The unit shall have two variable-speed pumps, with piping and valving permitting operation of the pumps individually, in series, and in parallel.

2) Due to the limited time period available, parts to be used shall be, as much as possible, stock, readily-available items.

3) The unit shall be self-contained, with a water reservoir. It shall be portable and mounted on a cart so that it can be moved to different locations in the building. It must be small enough for use of the building elevator.

4) The instrumentation shall be sufficient to determine the head-flow curves for the pumps, operating individually, in series, and in parallel. Instrumentation shall also be provided for determining the pump efficiency.

5) The instrumentation shall be modern, with digital readout.

"Proceedings of the 2002 American Society for Engineering Education Annual Conference \& Exposition, Copyright 2002, American Society for Engineering Education” 
6) The demonstration unit shall be provided with a take-off connection, having a normally closed valve, so that additional piping may be added to the system, if desired, at a future date.

7) The demonstration unit shall be aesthetically pleasing. It shall be an attractive addition to the mechanical engineering laboratories.

8) Work shall be completed in a timely fashion; that is, within the semester. It shall also be completed within the $\$ 4,979$ budgeted amount obtained from ASHRAE under the ASHRAE Undergraduate Senior Project Program.

After setting forth the design criteria, the professor reviewed the pertinent sections of fluid mechanics; that is, incompressible flow in pipes and pump performance. He presented some sample pipe flow problems and discussed pump operating curves. He discussed the selection of instrumentation, including the parameters to be measured and the use of pipe flow theory in determination of the ranges for the various sensors. Students met with the professor for about two hours weekly to submit progress reports, discuss problems encountered, and obtain guidance and suggestions.

\section{B. The Final Design}

This section discusses the final design in detail.

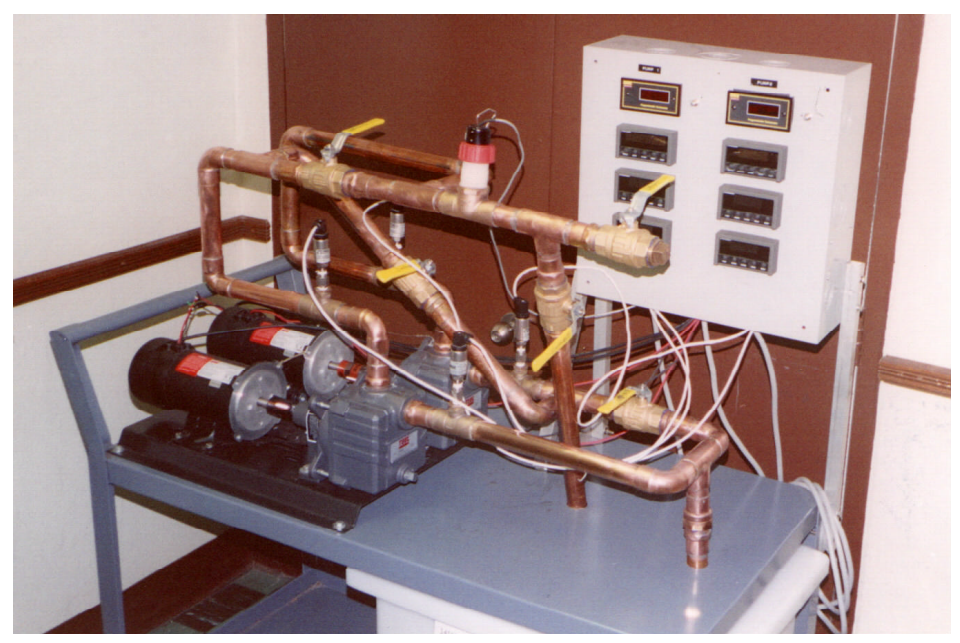

"Proceedings of the 2002 American Society for Engineering Education Annual Conference \& Exposition, Copyright 2002, American Society for Engineering Education" 
The pump system includes two (2) variable speed, motor-driven pumps, five (5) ball valves, 1-1/4 inch diameter Type L copper tubing, and a 30 gallon water tank. Instrumentation includes four (4) pressure sensors, two (2) tachometers for pump/motor speed determination, one (1) paddlewheel flow meter, and one (1) thin beam load cell used for determination of the torque and power inputs to the pump shaft. The equipment is mounted on a two-foot by four-foot cart having two shelves. The water tank is on the lower shelf and the pumps are mounted on the upper shelf. Instrumentation readouts and electrical controls are mounted in an electrical cabinet attached to the cart.

The following table lists the equipment items, including costs. The total equipment cost slightly exceeded the budgeted amount of $\$ 4,979$. This cost overrun was absorbed by Hofstra's Department of Engineering.

\section{EQUIPMENT ITEMS}

\section{QTY. DESCRIPTION $\quad$ PRICE}

The Pump Assembly - Motors and Pump Heads

$\begin{array}{llr}2 & \begin{array}{l}\text { Dayton 1/2 HP Permanent Magnet DC } \\ \text { Motor (Grainger \#2M168) }\end{array} & \$ 446.50 \\ 2 & \begin{array}{l}\text { Dart Variable Speed Control for Motors } \\ \text { (Grainger \#2M510) }\end{array} & 139.50 \\ 2 & \text { Pump Head (Grainger \#1P884) } & 273.50 \\ 4 & \text { Coupling Body (Grainger \#4X179) } & 11.52 \\ 2 & \text { Buna-N Spider (Grainger \#1X408) } & 3.46\end{array}$

Cart \& Mounting Items

$1 \quad$ Stock Truck (48" x 24"; 2000 lb. Capacity) 272.50

$1 \quad$ Mounting Base for Motor \& Pump Head 35.10

Misc. $\quad$ Casters \& Mounting Hardware $\quad 44.74$

"Proceedings of the 2002 American Society for Engineering Education Annual Conference \& Exposition, Copyright 2002, American Society for Engineering Education” 
$\underline{\text { Tank }}$

130 gallon, high density polyethylene 126.58

Rectangular Tank; 24"L x 18"W x 18"D

(McMaster-Carr \#1255K66)

1 Tank Bulkhead Fitting; 1/2" pipe size;

14.13

polypropylene

(McMaster-Carr \#36895K141)

Piping

$20 \mathrm{ft} . \quad$ Type L; 1-1/4 hard copper tube 274.83

$11 \quad 1-1 / 4$ Copper Elbows

5 1-1/4 Copper Tees

14 1-1/4 C-M Adapters

Misc. $\quad$ Fittings

Valves

5

1-1/4 Brass Ball Valves $\quad 91.90$

(McMaster-Carr \#47865K26)

Electrical

1 Electrical Steel Service Box (for mounting meters)

(18" x $18 "$ x 6")

Pressure Sensors

2

Pressure Transmitter (0-15 psig)

450.00

(Omega Engineering \#PX215-015GI)

1

Pressure Transmitter (0-30" Vacuum)

225.00

(Omega Engineering \#PX215-30VACI)

225.00

(Omega Engineering \#PX215-30V15GI)

4

Pressure Snubbers (water use)

40.00

(Omega Engineering \#PS-4E) 
Flow Sensor

$1 \quad$ Paddle Wheel Sensor

242.00

(Omega Engineering \#FP-5300)

1

1-1/4" Copper Fitting for Flow Sensor

103.00

(Omega Engineering \#FP-5312CU)

1 Polypro Plug for Flow Sensor

(Omega Engineering \#FMK-31536-1)

\section{Torque Sensor}

1

Thin Beam Load Cell

69.00

1

(Omega Engineering \#LCL-005)

Mounting Kit for Load Cell

30.00

(Omega Engineering \#LCM-CL1)

\section{Speed Sensor}

2

Pulse Generators (for Motor RPM)

101.70

(Grainger \# 6Z392)

Digital Display Units

4

Panel Meter 115 VAC Red LED

780.00

For pressure sensors

(Omega Engineering \#DP24-E)

1

Rate Meter/Totalizer

For flow sensor

(Omega Engineering \#DPF701)

1

Strain Gage Meter

For load cell

(Omega Engineering \#DP25-S)

2

Tachometer/Ratemeter

378.50

For motor speed sensor

(Grainger \#6Z390) 
Miscellaneous

Analog pressure gages for system testing;

Globe valves; extra mounting plate; extra fittings

$\underline{\text { TOTAL COST }}=\$ 5,123$

\section{Design Alternatives and Considerations}

This section discusses some alternatives considered in arriving at the final design. It also discusses some problems related to the system design.

1) One pump motor is bolted to the cart. The other motor is supported with bearings on its shaft so that the motor body is free to rotate during operation. A torque arm, in conjunction with a thin beam load cell, is used as an electric motoring dynamometer to determine the power input to the pump shaft, and ultimately determine the pump efficiency. Casters were originally used to support the motor and permit rotation, but these proved to have excessive friction. Hence the casters were replaced by ball bearings. The load cell and digital readout were installed since the objective was to have digital readout for all instrumentation. An alternative would have been to measure the load using a spring hanging scale. This would have been much cheaper and simpler to implement. Use of the load cell required considerable attention to achieve the needed alignment for accurate operation.

2) To minimize pressure drops in the piping, it was decided to use 1-1/4 inch copper tubing. This turned out to be troublesome as it was difficult to lay out all the needed piping, valves, and instrumentation on a small portable cart. An acceptable layout was achieved, but in retrospect it probably would have been better to use $3 / 4$ or one inch tubing. The 1-1/4 inch tubing also created problems related to air pockets in the system. It was difficult to vent the system. Finally, the large piping made it impossible to achieve straight piping runs before and after the flow sensor. These straight lengths are prescribed by the flowmeter manufacturer. As a result of the lack of sufficient straight lengths, the flow meter output exhibits some fluctuation for flow rates above $10 \mathrm{gpm}$.

"Proceedings of the 2002 American Society for Engineering Education Annual Conference \& Exposition, Copyright 2002, American Society for Engineering Education” 
3) Ball valves were selected for directing the flow for individual pump operation, series operation, and parallel operation and also for flow control. Originally, the plan was to use gate valves for flow path selection and a globe valve for flow control. These valves, however, have significantly greater flow resistance than ball valves. It was decided to use ball valves throughout the experiment to minimize pressure drops in the piping system and maximize the flow rates achievable by the pumps.

4) The water tank has a capacity of 30 gallons. Although dimensional information in catalogs indicates that the tank would easily fit on the lower shelf of the cart, this was not the case. About one inch of the top of the tank had to be cut off. In retrospect, a 30 gallon tank was not needed. A 20 gallon tank, with its smaller dimensions, would have been entirely satisfactory.

5) As built, the inlet and outlet lines for the pumps are copper tubing extending into the tank. This makes it very difficult to remove the tank from the cart for cleaning. It would have been much better to have used flexible plastic tubing for the inlet and outlet lines.

6) The pump system generates considerable noise even though it is mounted on a very sturdy cart. The noise most likely could have been reduced by selecting variable speed pumps with built-in motors rather than having separate motors and pump heads with couplings between them. The pumps with integral motors, however, are very expensive and beyond the budget of the project. Unfortunately, the excessive noise generation was not given detailed consideration until after the entire pump system and piping had been assembled and major changes could not be made to the pump/motor mountings. Foam pads were inserted between the pump mounting plate and the cart, but this did not significantly reduce the noise. The main problem is that the cart, even though very sturdy and of heavy sheet metal, is nevertheless of metal, and therefore susceptable to noise and resonant vibration due to the rotating equipment. In future lab experiments involving rotating or vibrating equipment, wood or wood-laminate carts will probably be used instead of metal ones.

\section{Construction}

A mock-up of the piping system, including valves, was done using paper and cardboard. As noted above, difficulty was experienced in fitting all of the piping system within the confines of the cart. However, this was finally accomplished, and construction began.

The motors and pumps were mounted on the top shelf of the cart, and the tank was placed on the bottom shelf. The piping system was dry-fitted and the final piping configuration was determined. Then the many pipe joints were solder-sweated. The system was pressure-tested. A few joints were found to be leaking, and these joints were repaired.

"Proceedings of the 2002 American Society for Engineering Education Annual Conference \& Exposition, Copyright 2002, American Society for Engineering Education” 
Cut-outs were made in the electrical service box for the panel meters, and the meters were mounted in the box. The electrical box was wired, and the box was mounted on the back of the cart. The sensors were mounted on the piping system, and wiring was installed between the sensors and the panel meters.

The motors were turned-on and the pumps were operated at various speeds. Before taking data, assurance of proper operation of the speed pulse generators was obtained through comparison with an optical tachometer. The pressure measuring systems were zeroed to room atmospheric pressure, and the flow measuring system was zeroed.

\section{Experimental Results}

Many experimental results have been obtained from the pump demonstration unit, including pump performance curves for the pumps operating individually, in parallel, and in series. As an example, the following graph shows the performance curves for the two pumps operating individually at their rated speed of 1725 RPM.

\section{Pump Performance for Individual Pump Operation (1725 RPM)}

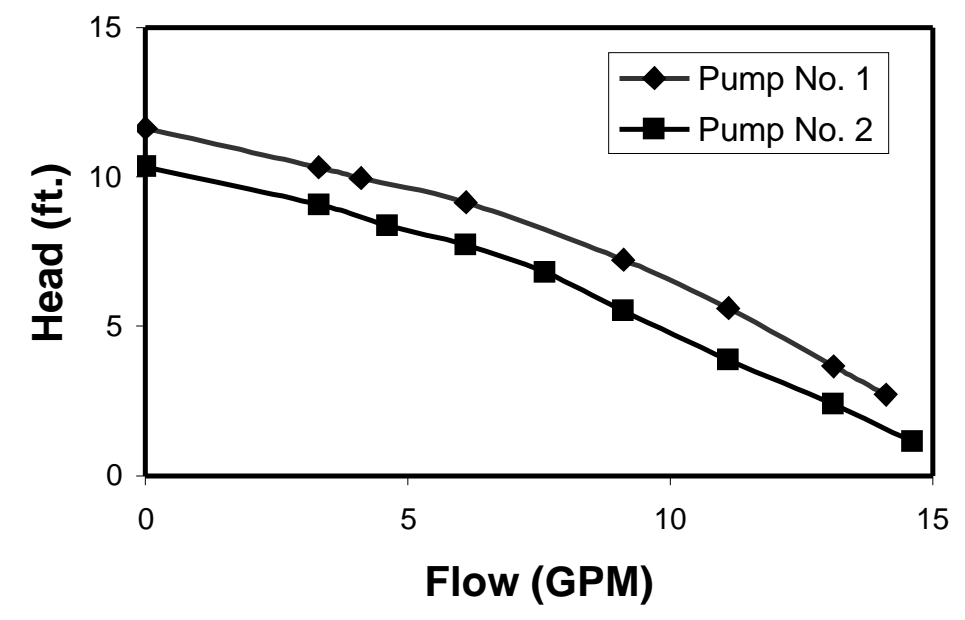

"Proceedings of the 2002 American Society for Engineering Education Annual Conference \& Exposition, Copyright 2002, American Society for Engineering Education” 


\section{Non-Technical Aspects of the Project, Including Suggestions}

Several non-technical problems were encountered during the project. This section discusses these problems and makes suggestions for their avoidance or minimization.

\section{A. Project Organization and Scheduling}

Being a one-semester project, it is necessary to get going immediately at the beginning of the semester and continue at a fast pace. The project got off to a slow start in that the professor had to spend considerable time reviewing fluid mechanics topics which the student s had apparently forgotten over the winter break. The review was needed for the system design aspects of the course, but too much time was spent in class on it. In the future, notes will be handed-out and only minimal class time will be devoted to review of previously learned theory.

A complete overview of the course schedule should be presented at the first class meeting. This schedule should indicate definite dates for major action items and milestones such as conceptual design, determination of final design, release of purchase orders for equipment, construction of the system, testing of the system, initial draft of the project report, etc. This will emphasize to the students the limited time available for the various items, and hopefully prod the $m$ to keep moving.

\section{B. Interactions Between Faculty, Students, and Lab Technicians}

Although the objective is certainly to have the students work with minimal supervision, it is definitely necessary to keep track of the students' progress or lack thereof. Weekly written and oral progress reports are necessary, and the professor should not hesitate to take a more active role in project direction if he/she sees that students are proceeding too slowly or have encountered major obstacles. It may be necessary at certain times to assign specific tasks for the students to accomplish before the next class meeting.

In such a construction project there is considerable interaction between the students and the lab technician(s). For example, in this project the technicians assisted greatly in soldering the piping and wiring of the instrumentation. The lab technicians play a significant role in the successful completion of the project, and the students should recognize and appreciate this role. They should request the technicians' assistance tactfully and not have unrealistic demands during the hectic final weeks of the semester.

"Proceedings of the 2002 American Society for Engineering Education Annual Conference \& Exposition, Copyright 2002, American Society for Engineering Education” 


\section{Students' Motivation and Abilities}

The professor looked upon this project as being exciting, real, and practical. It gave the students the opportunity to design and build a system which illustrates several fluid mechanics principles discussed in lecture class. It is also unusual for students to be given such a large amount of money $(\$ 5,000)$ for use in their senior design project. Nevertheless, despite the professor's considerable efforts, some students exhibited very little interest and motivation. Furthermore, the professor was surprised to observe the lack of manual construction skills on the part of many students. There are no easy solutions to these problems.

\section{Division of Work Among Students}

As often happens, it appeared that certain students were working much more on the project than others. For grading purposes and to keep the workload among the students as uniform as possible, it is necessary to have the different students assigned specific tasks of the project. Preferably the students will make the job assignments themselves, but the professor may have to review the assignments and modify them if necessary.

\section{E. Equipment Procurement}

Many delays were experienced in the procurement of equipment. The purchase order procedure is tedious, with approvals required from many individuals even though the grant money is in the bank. Approvals are needed from the department head, the associate dean, and the grants office. The purchasing department places the purchase order. When the equipment has arrived, it goes to receiving and stores where it may remain for a considerable time until union personnel can deliver it to the lab. Each step involves a potential delay, and it is definitely necessary to keep a constant watch on the progress of purchase requests. It is often better, if the system permits, for the professor to avoid the hassle and place orders for equipment directly with the vendors. This can be done if the cost of the item is small enough and multiple bids are not required. Of course, it is usually necessary for the professor to use his/her own credit card and receive reimbursement from the university. Despite this drawback, the author uses this approach as much as possible to avoid hassles and minimize delay.

\section{Conclusion}

This project has provided a very significant design/construction experience for the students. It has been very successful, and the pump experiment has been incorporated into the mechanical engineering laboratories and used regularly in the senior level laboratory course ENGG 170, "Mechanical Engineering Laboratory II".

"Proceedings of the 2002 American Society for Engineering Education Annual Conference \& Exposition, Copyright 2002, American Society for Engineering Education" 


\section{Acknowledgments}

Many thanks to ASHRAE for providing the funds for the equipment of this project under its Undergraduate Senior Project Grant Program.

\section{CHARLES H. FORSBERG}

Charles H. Forsberg is an Associate Professor of Engineering at Hofstra University, where he teaches courses in the thermal/fluids area and is coordinator of the mechanical engineering program. He received a B. S. in Mechanical Engineering from the Polytechnic Institute of Brooklyn (now Polytechnic University), and an M. S. in Mechanical Engineering and $\mathrm{Ph}$. D. from Columbia University. He is a Licensed Professional Engineer in New York State.

"Proceedings of the 2002 American Society for Engineering Education Annual Conference \& Exposition, Copyright 2002, American Society for Engineering Education” 